\title{
Impact of restricting diagnostic imaging reimbursement for uncomplicated low back pain in Ontario: a population- based interrupted time series analysis
}

\author{
Benjamin Fine MD SM, Susan E. Schultz MA MSc, Lawrence White MD, David Henry MB ChB
}

\section{Abstract}

Background: In 2012, the Ontario government withdrew public insurance coverage of imaging tests for uncomplicated low back pain. We studied the impact of this restriction on test ordering by physicians.

\begin{abstract}
Methods: We compared the numbers of lumbar spine radiography, computed tomography (CT) and single-segment magnetic resonance imaging (MRI) studies ordered by physicians in the 3 years before and after the policy change. We linked claims data from the Ontario Health Insurance Program with physician details to calculate rates per test-ordering physician. We compared changes in rates of monthly test ordering by family physicians and specialists before and after the policy change using segmented regression analysis of interrupted time series data.
\end{abstract}

Results: The number of lumbar spine radiography and spine CT studies ordered by family physicians decreased by 98597 (28.7\%) and 17499 (28.7\%), respectively, in the year after the policy change; there was little change in ordering by specialists. The number of lumbar spine radiography studies ordered per family physician by month decreased by 0.81 tests $(p<0.001)$ after the intervention, followed by a smaller rebound increase that remained below baseline. Monthly ordering of spine CT per family physician declined by 0.1 tests $(p<0.001)$, and that of limited spine MRI rose before the intervention, decreased by 0.18 tests $(p<0.001)$ after the intervention, then started to rise again. Monthly ordering of limited spine MRI by specialists, which had been stable before the policy change, decreased by 0.1 tests per specialist $(p<0.001)$ afterward, then rose to preintervention levels.

Interpretation: The restriction in coverage of imaging tests caused a larger decrease in test ordering by family physicians than by specialists and a larger, more sustained reduction in the use of lumbar spine radiography and spine CT than of spine MRI.

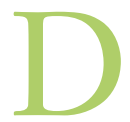
octors frequently order imaging tests for patients with uncomplicated back pain, despite evidence that this does not improve the quality of care or outcomes in many settings. ${ }^{1,2}$ Overuse of imaging tests adds to health care costs and may expose patients to ionizing radiation, with little benefit and occasional harm. ${ }^{3,4}$ Echoing the published guidelines, ${ }^{5-8}$ Choosing Wisely campaigns in Canada and around the world have identified imaging for uncomplicated low back pain, where no clinical "red flags" (e.g., trauma, infection, radiculopathy, malignant disease) are present, as a low-value intervention that should not be performed. ${ }^{9-11}$ Despite this, radiographic, magnetic resonance imaging (MRI) and computed tomography (CT) studies of the spine continue to be performed in large numbers., ${ }^{3,12-14}$

Changing health professional practice is not simple, and systematic reviews have documented variable results of interventions. ${ }^{15}$ Some interventions, such as clinical decision support, preauthorization and targeted reminders, have shown short-term success in reducing use of imaging for low back pain, whereas others, such as guideline dissemination, have not. ${ }^{15-17}$

One option available to payers, regulating access to imaging tests through changes in reimbursement, ${ }^{17,18}$ has not been systematically evaluated at the population level. In April 2012, the government of Ontario removed reimbursement for diagnostic imaging for uncomplicated low back pain from the Schedule of Benefits. ${ }^{19}$ There was no direction on who would pay for inappropriate studies or how those would be detected. This study was designed to evaluate the impact of this change on the use of imaging tests for low back pain in Ontario.

\section{Competing interests: None declared.}

This article has been peer reviewed.

Correspondence to: Benjamin Fine, ben.fine@utoronto.ca

CMAJ Open 2017. DOI:10.9778/cmajo.20160151 


\section{Methods}

\section{Setting and design}

All medically necessary procedures (including imaging studies) in Ontario (population about 13.5 million) are funded by the Ontario Health Insurance Plan. In April 2012, the government of Ontario modified the Schedule of Benefits for Physician Services under the Health Insurance Act (Box 1). ${ }^{19,20}$ We assessed the impact of the policy change by comparing the numbers of imaging tests for uncomplicated low back pain ordered before and after the change. We used the numbers of imaging tests ordered for other indications as a control.

\section{Sources of data}

Based on a review of all available billing codes, we selected the following investigations: lumbar spine radiography (X028, X205, X206), spine CT (X415, X416, X128) and singlesegment spine MRI (X490, X493). We used the Ontario Health Insurance Plan billing data held at the Institute for Clinical Evaluative Sciences (ICES) for the period Jan. 1, 2009, to Mar. 31, 2015. These data were linked to the ICES physician database, which contains information on the ordering physician, including specialty. These data sets were linked with the use of unique encoded identifiers and analyzed at ICES. We included all physicians in our analyses, categorized as family physicians or specialists. To create a control series of imaging tests, which should not have been affected by the policy change, we retrieved data on brain CT, brain MRI and whole spine MRI. We related the number of imaging tests to the number of physicians rather than the population covered, as the intervention being assessed was designed to change physician practice.

\section{Statistical analysis}

We analyzed overall test ordering for the 3 imaging modalities during the 3 years before and after the policy change (April 2012). We compared ordering on an annual basis before and after the policy change. We calculated monthly ordering rates for family physicians and specialists by dividing the total number of tests ordered per month by either group by the total number of physicians who ordered the test at least once during that calendar year. We used segmented regression analysis of interrupted time series data to assess changes in monthly test ordering separately by family physicians and by specialists who ordered at least 1 test over 72 consecutive months. This approach allowed us to estimate the immediate impact of the policy change as measured by a change in the intercept of the slopes before and after the intervention while

Box 1: Amendments to Ontario Schedule of Benefits regarding diagnostic imaging for chronic low back pain

- Radiography, computed tomography or magnetic resonance imaging studies of the lumbar spine are eligible for payment only when rendered for low back pain with suspected or known pathology

- Examples include but are not limited to: infection, tumour, osteoporosis, ankylosing spondylitis, fracture, inflammatory process, radicular syndrome and cauda equine syndrome adjusting for both the overall secular trend and the autocorrelative nature of the data. We used the AUTOREG procedure (SAS Institute Inc.) to test for autocorrelation by means of the Durbin-Watson statistic. In cases in which the DurbinWatson statistic was significant, we performed correction for autocorrelation. The outputs of the analyses were secular trends, autocorrelation, the pre-post change in ordering rates and the pre- and postregression slopes.

\section{Ethics approval}

The Sunnybrook Health Sciences Centre Research Ethics Board has an agreement with ICES that allows it to conduct research using the anonymized administrative databases held at ICES without need for independent research ethics board review. ICES is named as a Prescribed Entity under Section 45 of the Personal Health Information Protection Act (Ontario Regulation 329/04, Section 18). Under this designation, ICES can receive and use health information without consent for the purposes of analysis and compiling statistical information about the health care system of Ontario.

\section{Resullts}

\section{Triennial numbers of imaging tests ordered by physicians}

The average annual numbers of tests ordered in the 3 years before and after the policy change are presented in Figure 1. Following the policy change, there were declines in the numbers of lumbar spine radiography and spine CT examinations but not single-segment MRI studies, whose numbers rose slightly. In comparison, annual numbers of head CT examinations fell marginally, and numbers of head MRI examinations and whole spine MRI testing rose. The costs to the Ontario Health Insurance Plan of lumbar spine radiography fell, from an annual average of $\$ 17.04$ million between 2009/10 and $2011 / 12$ to $\$ 11.97$ million in the year after the policy change. Costs of other imaging modalities were little affected (data available from authors on request).

\section{Annual numbers of imaging tests and per-physician ordering rates}

\section{Lumbar spine radiography}

In this section and subsequent sections, the denominators used in calculating ordering rates were the numbers of physicians who ordered 1 or more imaging tests during the calendar year.

In the year after the policy change (2012/13), there was a reduction of $28.7 \%$ in the annual total number of lumbar spine radiography studies ordered by family physicians compared to the average ordered annually during the baseline period (Table 1). The average number of lumbar spine radiography studies ordered per family physician decreased by a proportionally greater amount $(31.8 \%)$ and rebounded less in $2013 / 14$ than the total number of tests ordered annually.

Specialists ordered fewer lumbar spine radiography studies than did family physicians, because of both the smaller number of specialists ordering tests and lower rates per test-ordering 
physician (Table 1). The decrease in ordering after the policy change was small $(-4.0 \%)$, and ordering returned to preintervention levels the following year.

\section{Single-segment spine magnetic resonance imaging}

After the policy change, there was a small decline $(-5.0 \%)$ in the per-physician ordering rate for spine MRI among family physicians (Table 1). However, the total number of singlesegment spine MRI studies ordered by family physicians rose slightly because of an increase in the number of family physicians ordering this investigation. In 2013/14 and 2014/15, there were increases in both the number of family physicians ordering spine MRI and the rate of ordering per family physician.

Specialists ordered about half the number of spine MRI examinations as family physicians (Table 1). However, the ordering rate per physician was about $10 \%-20 \%$ higher than that among family physicians. The policy change had a similar effect to that seen for family physicians: a transient small decline $(-8.5 \%)$ in the per-physician ordering rate against a background of increasing numbers of specialists ordering tests, resulting in an increase in the total annual numbers of tests ordered.

\section{Spine computed tomography}

The number of family physicians who ordered spine CT and the number of tests ordered per family physician declined by $7.5 \%$ and $22.8 \%$, respectively, after the policy change, resulting in an overall decrease in the number of spine CT studies of $28.7 \%$ compared to baseline (Table 1 ).
Specialists ordered about one-third the number of spine CT studies as did family physicians (Table 1 ). The apparent impact of the policy change in 2012/13 was substantially less than that seen among family physicians. The total number of tests ordered, rate per test-ordering physician and number of physicians ordering the test all rebounded in 2013/14, but this trend was not sustained in 2014/15.

\section{Monthly ordering}

The number of lumbar spine radiography, single-segment spine MRI and spine CT studies ordered per physician by month are presented in Figure 2, Figure 3 and Figure 4, respectively. The outputs from the interrupted time series analyses are given in Table 2. The data for the first 2 months after the policy change were omitted from the analyses to improve the stability of the estimates of the pre- and postintervention slopes.

\section{Lumbar spine radiography}

There was a borderline significant $(p=0.047)$ negative slope in ordering of lumbar spine radiography by family physicians before the policy change and a decline of around 0.8 tests/ month per physician $(p<0.001)$ after the change, followed by a significant rebound in ordering, which appeared to be levelling off by the end of the follow-up period (Figure 2). Ordering rates remained about 0.5 tests/month below baseline levels after the policy change. In the case of specialists, there was no significant slope either before or after the policy change and no significant decrease in ordering because of the intervention (Table 2).

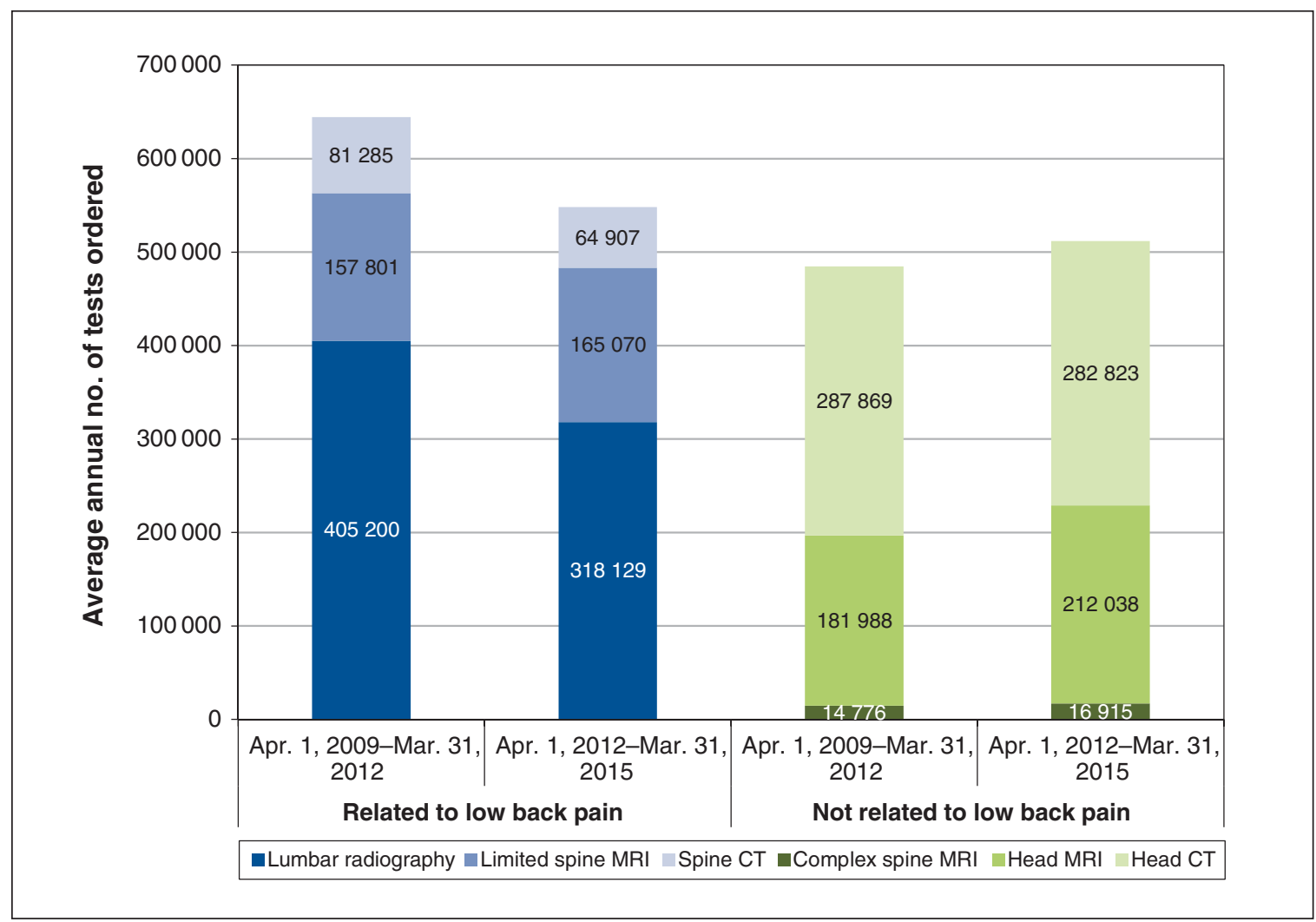

Figure 1: Average annual numbers of imaging tests related and not related to low back pain in Ontario during the 3 years before and after the policy change (Apr. 1, 2012). 
Single-segment spine magnetic resonance imaging

Before the policy change, the rate of ordering of singlesegment spine MRI by family physicians showed a significant $(p<0.001)$ upward trend; the rate among specialists was stable
(Figure 3, Table 2). The decrease in ordering rates after the policy change was $0.18 /$ month for family physicians and $0.10 /$ month for specialists. Ordering rates then rebounded significantly (Table 2) and by the end of the follow-up period were

\begin{tabular}{|c|c|c|c|c|c|c|c|c|}
\hline Test; specialty; measure & $\begin{array}{c}2009 / 10 \\
\text { to } 2011 / 12 \\
\text { (baseline) }\end{array}$ & $2012 / 13$ & $\begin{array}{l}\% \text { change } \\
\text { from } \\
\text { baseline }\end{array}$ & $2013 / 14$ & $\begin{array}{c}\% \text { change } \\
\text { from } \\
\text { previous } \\
\text { year }\end{array}$ & $2014 / 15$ & $\begin{array}{l}\% \text { change } \\
\text { from } \\
\text { previous } \\
\text { year }\end{array}$ & $\begin{array}{c}\% \\
\text { change } \\
\text { from } \\
\text { baseline }\end{array}$ \\
\hline \multicolumn{9}{|l|}{ Lumbar spine radiography } \\
\hline \multicolumn{9}{|l|}{ Family physician } \\
\hline No. of tests per year, mean & 342949 & 244352 & -28.7 & 271439 & 11.1 & 275082 & 1.3 & -19.8 \\
\hline $\begin{array}{l}\text { No. of tests per physician } \\
\text { per year, mean (range) }\end{array}$ & $\begin{array}{c}31.4 \\
(1-628)\end{array}$ & $\begin{array}{c}21.4 \\
(1-421)\end{array}$ & -31.8 & $\begin{array}{c}23.1 \\
(1-481)\end{array}$ & 7.9 & $\begin{array}{c}23.7 \\
(1-418)\end{array}$ & 2.6 & -24.5 \\
\hline $\begin{array}{l}\text { No. of physicians who } \\
\text { ordered test }\end{array}$ & 10924 & 11426 & 4.6 & 11755 & 2.9 & 11626 & -1.1 & 6.4 \\
\hline \multicolumn{9}{|l|}{ Specialist } \\
\hline No. of tests per year, mean & 62251 & 58540 & -6.0 & 61927 & 5.8 & 62049 & 0.2 & -0.3 \\
\hline $\begin{array}{l}\text { No. of tests per physician } \\
\text { per year, mean (range) }\end{array}$ & $\begin{array}{c}12.6 \\
(1-1049)\end{array}$ & $\begin{array}{c}12.1 \\
(1-980)\end{array}$ & -4.0 & $\begin{array}{c}12.4 \\
(1-938)\end{array}$ & 2.5 & $\begin{array}{c}12.5 \\
(1-937)\end{array}$ & 0.8 & -0.8 \\
\hline $\begin{array}{l}\text { No. of physicians who } \\
\text { ordered test* }\end{array}$ & 4956 & 4850 & -2.1 & 4977 & 2.6 & 4949 & -0.6 & -0.1 \\
\hline \multicolumn{9}{|l|}{ Single-segment spine MRI } \\
\hline \multicolumn{9}{|l|}{ Family physician } \\
\hline No. of tests per year, mean & 90890 & 91640 & 0.8 & 103369 & 12.8 & 105155 & 1.7 & 15.7 \\
\hline $\begin{array}{l}\text { No. of tests per physician } \\
\text { per year, mean (range) }\end{array}$ & $\begin{array}{c}9.9 \\
(1-308)\end{array}$ & $\begin{array}{c}9.4 \\
(1-186)\end{array}$ & -5.0 & $\begin{array}{c}10.2 \\
(1-204)\end{array}$ & 8.5 & $\begin{array}{c}10.3 \\
(1-172)\end{array}$ & 1.0 & 4.0 \\
\hline $\begin{array}{l}\text { No. of physicians who } \\
\text { ordered test* }\end{array}$ & 9116 & 9774 & 7.2 & 10181 & 4.2 & 10250 & 0.7 & 12.4 \\
\hline \multicolumn{9}{|l|}{ Specialist } \\
\hline No. of tests per year, mean & 43574 & 43738 & 0.4 & 47225 & 8.0 & 48072 & 1.8 & 10.3 \\
\hline $\begin{array}{l}\text { No. of tests per physician } \\
\text { per year, mean (range) }\end{array}$ & $\begin{array}{c}11.8 \\
(1-1093)\end{array}$ & $\begin{array}{c}10.8 \\
(1-926)\end{array}$ & -8.5 & $\begin{array}{c}11.2 \\
(1-1029)\end{array}$ & 3.7 & $\begin{array}{c}11.4 \\
(1-901)\end{array}$ & 1.8 & -3.4 \\
\hline $\begin{array}{l}\text { No. of physicians who } \\
\text { ordered test* }^{*}\end{array}$ & 3702 & 4040 & 9.1 & 4204 & 4.0 & 4223 & 0.4 & 14.1 \\
\hline \multicolumn{9}{|l|}{ Spine CT } \\
\hline \multicolumn{9}{|l|}{ Family physician } \\
\hline No. of tests per year, mean & 60966 & 43467 & -28.7 & 46975 & 8.1 & 45047 & -4.1 & -26.1 \\
\hline $\begin{array}{l}\text { No. of tests per physician } \\
\text { per year, mean (range) }\end{array}$ & $\begin{array}{c}7.9 \\
(1-190)\end{array}$ & $\begin{array}{c}6.1 \\
(1-138)\end{array}$ & -22.8 & $\begin{array}{c}6.4 \\
(1-213)\end{array}$ & 4.9 & $\begin{array}{c}6.3 \\
(1-158)\end{array}$ & -1.6 & -20.2 \\
\hline $\begin{array}{l}\text { No. of physicians who } \\
\text { ordered test* }^{*}\end{array}$ & 7728 & 7147 & -7.5 & 7370 & 3.1 & 7147 & -3.0 & -7.5 \\
\hline \multicolumn{9}{|l|}{ Specialist } \\
\hline No. of tests per year, mean & 20319 & 18472 & -9.1 & 20900 & 13.1 & 20866 & -0.2 & 2.7 \\
\hline $\begin{array}{l}\text { No. of tests per physician } \\
\text { per year, mean (range) }\end{array}$ & $\begin{array}{c}6.3 \\
(1-248)\end{array}$ & $\begin{array}{c}5.8 \\
(1-277)\end{array}$ & -7.9 & $\begin{array}{c}6.3 \\
(1-334)\end{array}$ & 8.6 & $\begin{array}{c}6.5 \\
(1-336)\end{array}$ & 3.2 & 3.2 \\
\hline $\begin{array}{l}\text { No. of physicians who } \\
\text { ordered test* }\end{array}$ & 3229 & 3179 & -1.5 & 3292 & 3.6 & 3212 & -2.4 & -0.5 \\
\hline
\end{tabular}


above those seen during the preintervention period for both physician groups, remaining higher for specialists than family physicians.

\section{Spine computed tomography}

There were significant negative slopes in the rates of ordering of spine CT by both family physicians and specialists before the policy change. The higher rates for family physicians converged with those of specialists before the intervention (Table 2, Figure 4). The policy change was associated with a decline in ordering by family physicians of 0.1 test/month but no significant decline among specialists. Postintervention rates of test ordering were similar for the 2 groups and were stable.

\section{Specialty of ordering physicians}

The specialists who most commonly ordered the imaging tests were grouped according to the clinical settings in which they were likely to encounter patients with low back pain. Lumbar radiography studies were most often ordered by orthopedic surgeons or neurosurgeons (45.3/physician per year), followed by family physicians with emergency medicine training (27.8/ physician) and emergency medicine specialists (22.0/physician). For single-segment MRI, the highest ordering rates were for neurologists (67.6/physician), followed by physiatrists (physical medicine and rehabilitation specialists) (33.3/physician) and orthopedic surgeons or neurosurgeons (26.3/physician).

\section{Interpretation}

The most marked and most sustained effect of the policy change in coverage of imaging tests for uncomplicated low back pain in Ontario was the reduction in ordering of lumbar spine radiography by family physicians. In contrast, the restriction had no measurable effect on the ordering of radiography by specialists, whose preintervention ordering rates were less than half those of family physicians. The reduction in ordering of radiography by family physicians was not trivial. This modality accounts for a substantial proportion of imaging costs to the Ontario health care system. ${ }^{21}$ The reduction in costs we documented in this study was roughly $\$ 5$ million annually. Furthermore, radiography is a source of ionizing radiation, and Ontarians avoided the equivalent of natural radiation exposure for 40000 years. The policy change was associated with a shortlived reduction in ordering of single-segment MRI of the spine by both specialists and family physicians. However, the 2 groups differed in 1 important respect. Specialists had a stable

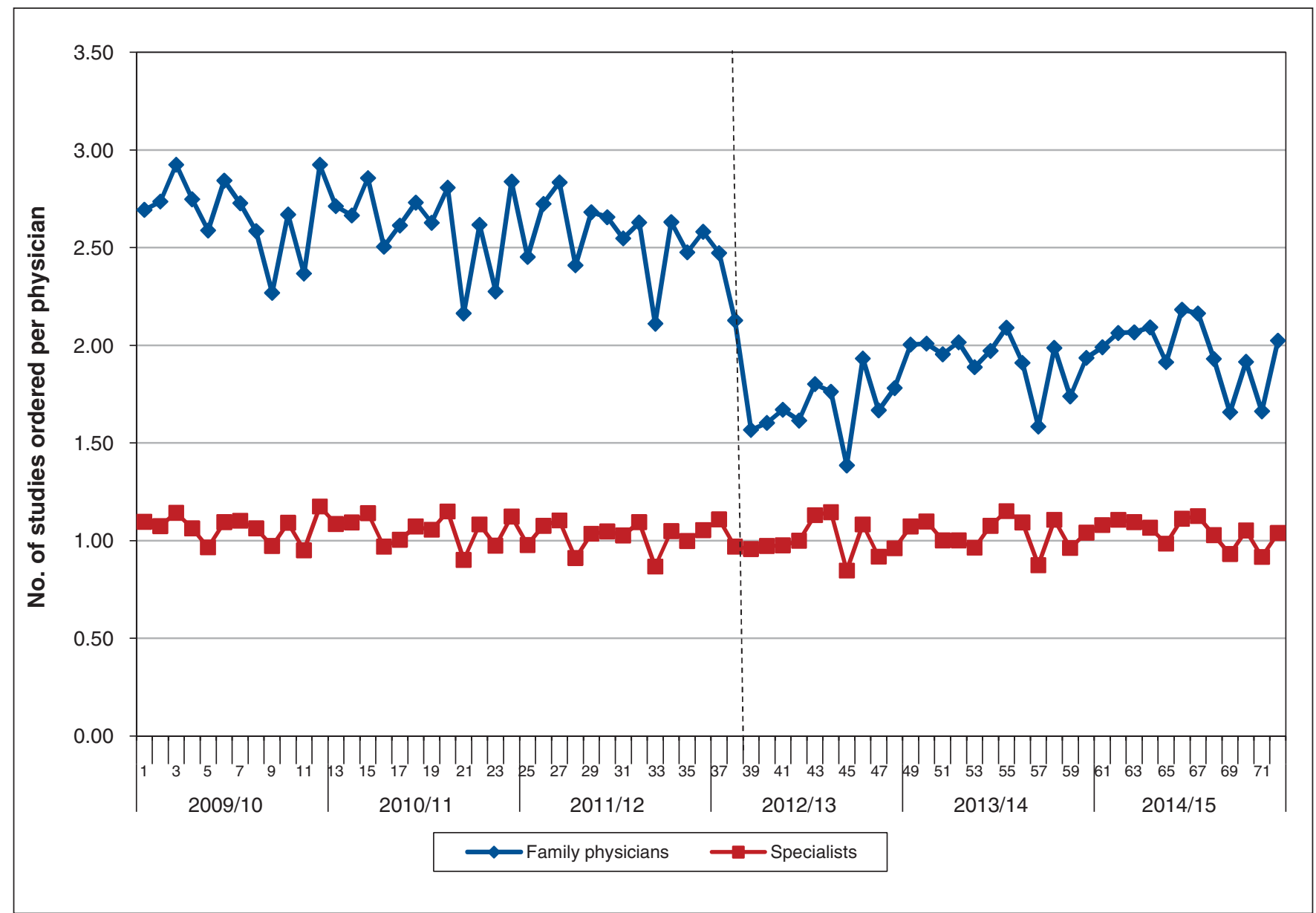

Figure 2: Number of lumbar spine radiography studies ordered per physician by month. All physicians who ordered a test during the year were included. Vertical dotted line denotes timing of policy change. 
and constant level of test ordering before the restriction and a shallow rebound afterward. In contrast, family physicians had a rising trend in ordering before the policy change and a greater decrease than that for specialists afterward; the rate then rose again, at about half the preintervention rate. This finding, together with the reduction in ordering of lumbar spine radiography, suggests that the ordering patterns of family physicians are more responsive to change than those of specialists. The policy change had a smaller effect on the ordering of spine CT against a background of decreasing use. CT ordering rates had decreased before the intervention, which likely reflected substitution by MRI, an increasingly accessible and, in many circumstances, more appropriate test. The policy change resulted in further, modest reductions in ordering of spine CT, followed by small rebounds, but this trend was not sustained in 2014/15.

There was evidence among both family physicians and specialists of a general movement away from lumbar spine radiography and spine CT, and toward single-segment MRI, which has greater sensitivity for several treatable disorders. ${ }^{3}$ The decrease in ordering of lumbar spine radiography may also reflect a decline in "lead-up" imaging before MRI. In a recent Canadian report, about half of patients undergoing MRI had previously undergone radiography or CT. ${ }^{21}$ In the current study, after the policy change, some physicians appear to have stopped the practice of ordering radiography before MRI, a positive result from the perspective of imaging appropriateness. Of note, we found no evidence of large-scale switching from lumbar spine radiography to newer, more expensive imaging tests; there was an overall reduction in the total number of imaging tests of around 100 000/year after the policy change.

The greatest difference between the 2 groups of physicians was seen with lumbar spine radiography. Compared to specialists, family physicians had higher ordering rates and a greater decrease in ordering after the policy change, which suggests a degree of overuse. This pattern has been reported previously. ${ }^{12}$ This may be explained in part by different patient populations. Specialists order many of their imaging studies in the examination and follow-up of patients with suspected or established spine disease, in whom imaging is indicated. Family physicians see healthier patients with a lower prevalence of serious spine disease. In addition, specialists may be more familiar with practice guidelines in spine imaging and may be more adherent to those guidelines and therefore less likely to change their practices after the intervention. Physicians order tests for nonclinical reasons, including patient demand and fear of litigation. ${ }^{22,23}$ It is possible that family physicians were aware of the limited value of lumbar spine radiography in the management of uncomplicated low back pain, and removal of coverage helped them reinforce this in discussions with patients. Finally, in interpreting our data, it is important to note that spine surgeons

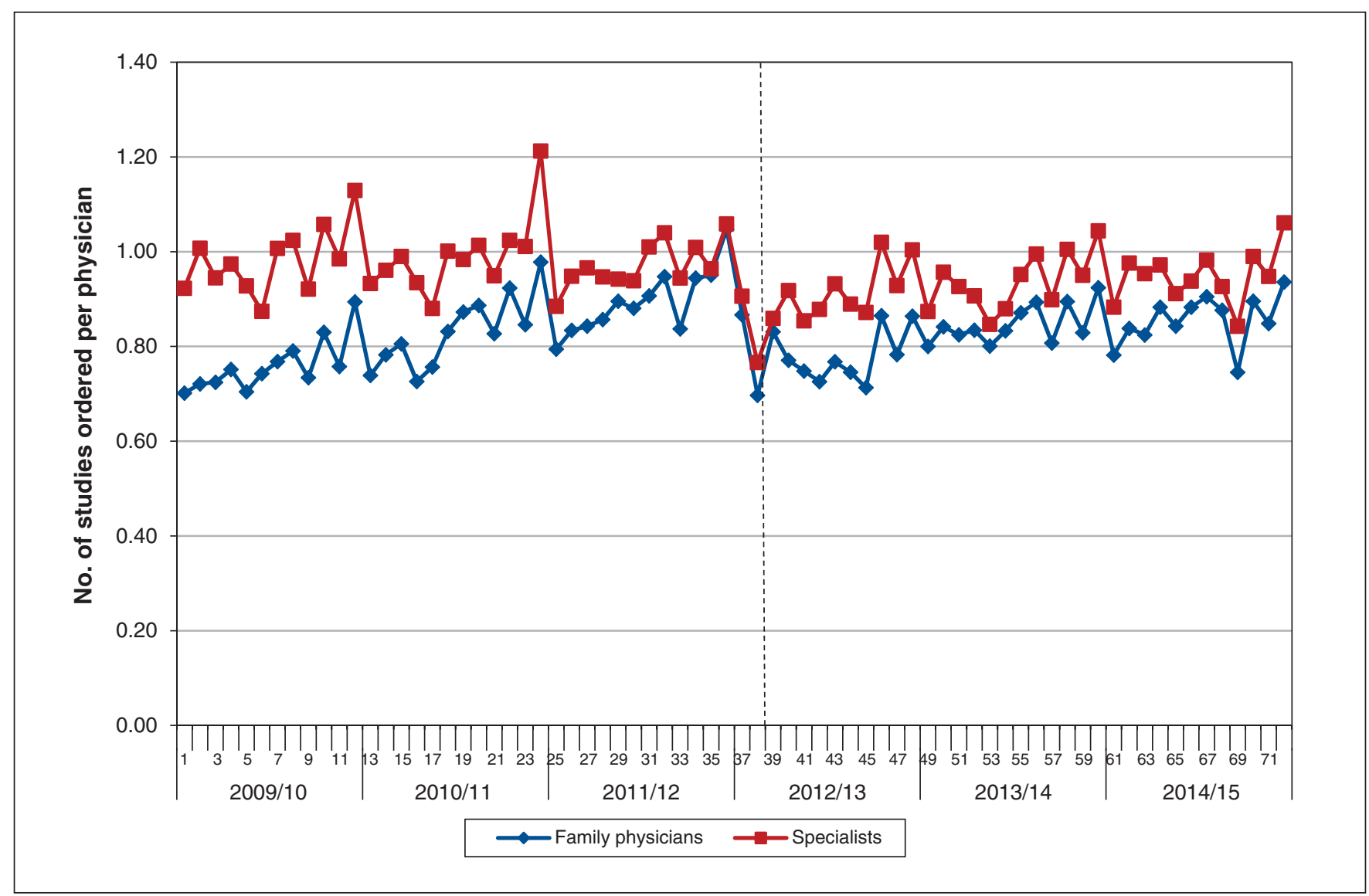

Figure 3: Number of single-segment spine magnetic resonance imaging studies ordered per physician by month. All physicians who ordered a test during the year were included. Vertical dotted line denotes timing of policy change. 


\section{OPEN}

\section{Research}

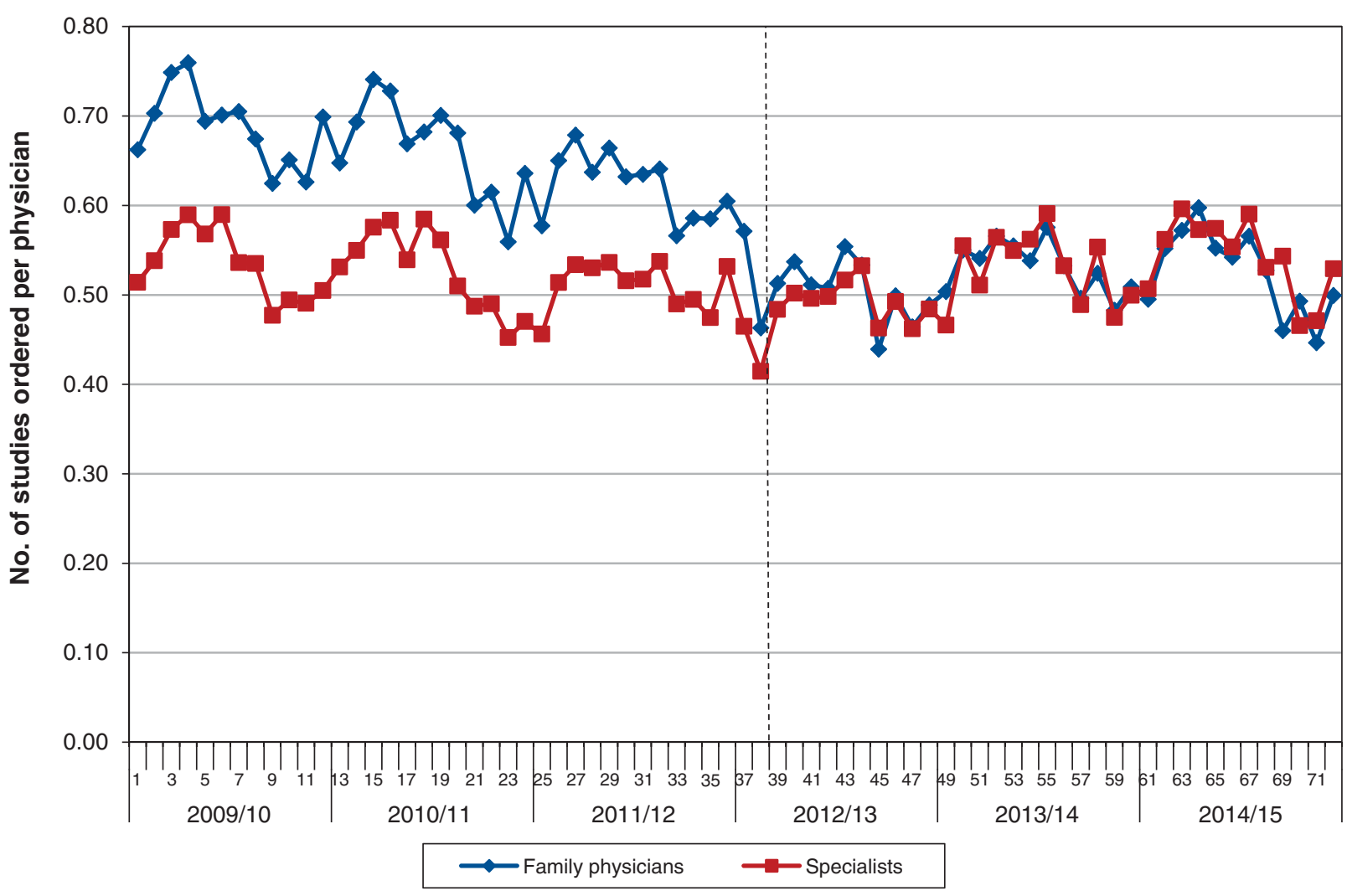

Figure 4: Number of spine computed tomography studies ordered per physician by month. All physicians who ordered a test during the year were included. Vertical dotted line denotes timing of policy change.

Table 2: Durbin-Watson statistic and regression parameter estimates after correction for autoregression where appropriate

\begin{tabular}{|c|c|c|c|c|}
\hline \multirow[b]{2}{*}{ Test; specialty } & \multirow[b]{2}{*}{$\begin{array}{l}\text { Durbin-Watson } \\
\text { statistic }\end{array}$} & \multicolumn{3}{|c|}{ Estimate $(95 \% \mathrm{Cl})$} \\
\hline & & $\begin{array}{c}\text { Time (overall secular } \\
\text { trend) }\end{array}$ & Effect of intervention & $\begin{array}{l}\text { Postintervention } \\
\text { slope }\end{array}$ \\
\hline \multicolumn{5}{|c|}{ Lumbar spine radiography } \\
\hline Family physician & 2.204 & $\begin{array}{c}-0.006 \\
(-0.0119 \text { to } 0.0001)\end{array}$ & $\begin{array}{c}-0.813 \\
(-0.9883 \text { to } 0.6377)\end{array}$ & $\begin{array}{c}0.0096 \\
(0.0036 \text { to } 0.0157)\end{array}$ \\
\hline Specialist & 2.522 & $\begin{array}{c}-0.0019 \\
(-0.0043 \text { to } 0.0005)\end{array}$ & $\begin{array}{c}-0.003 \\
(-0.0757 \text { to } 0.0697)\end{array}$ & $\begin{array}{c}0.0011 \\
(-0.0018 \text { to } 0.0039)\end{array}$ \\
\hline \multicolumn{5}{|l|}{ Limited spine MRI } \\
\hline Family physician & 2.231 & $\begin{array}{c}0.0067 \\
\text { (0.0051 to } 0.0083)\end{array}$ & $\begin{array}{c}-0.175 \\
(-0.2221 \text { to }-0.1279)\end{array}$ & $\begin{array}{c}0.0034 \\
(0.0018 \text { to } 0.0051)\end{array}$ \\
\hline Specialist & 2.294 & $\begin{array}{c}0.0009 \\
(-0.0011 \text { to } 0.0029)\end{array}$ & $\begin{array}{c}-0.102 \\
(-0.1603 \text { to } 0.0437)\end{array}$ & $\begin{array}{c}0.0022 \\
(0.0004 \text { to } 0.0041)\end{array}$ \\
\hline \multicolumn{5}{|l|}{ Spine CT } \\
\hline Family physician & 1.584 & $\begin{array}{c}-0.0028 \\
(-0.0039 \text { to }-0.0017)\end{array}$ & $\begin{array}{c}-0.099 \\
(-0.1230 \text { to }-0.0750)\end{array}$ & $\begin{array}{c}0.0001 \\
(-0.0012 \text { to } 0.0014)\end{array}$ \\
\hline Specialist & 2.091 & $\begin{array}{c}-0.0012 \\
(-0.0019 \text { to } 0.0005)\end{array}$ & $\begin{array}{c}-0.010 \\
(-0.0316 \text { to } 0.0116)\end{array}$ & $\begin{array}{c}0.0014 \\
(0.0001 \text { to } 0.0028)\end{array}$ \\
\hline
\end{tabular}

Note: $\mathrm{Cl}=$ confidence interval, $\mathrm{CT}$ = computed tomography, $\mathrm{MRI}=$ magnetic resonance imaging . 
often require spine imaging before accepting a patient referral from a family physician ( $84 \%$ of cases in 1 Canadian study ${ }^{21}$ ). This highlights the difficulty family physicians may have in imaging "appropriately" when they plan to refer their patients with low back pain to a specialist in Ontario.

\section{Limitations}

The indications for imaging tests are not recorded in the Ontario Health Insurance Plan, and we did not have access to the types of patient information needed to make a judgment about "appropriateness" of imaging. However, this would have been a source of bias in the study only if the prevalence of red flags were somehow causally related to the policy change, which is implausible. Undoubtedly, many imaging studies were done for reasons other than low back pain. In 1 Ontario study, only $22 \%$ of all outpatient spine MRI requisitions provided "back pain" as the indication. ${ }^{24}$ This does not invalidate the results of our study. Because we measured the entire population, we probably underestimated the true impact of the policy change on the target group: patients with uncomplicated low back pain. Many of the tests ordered during the study period were undoubtedly necessary. In previous studies, including 1 that reviewed the clinical history provided on requests for imaging studies in Ontario, the authors concluded that $28 \%-50 \%$ of outpatient lumber spine MRI examinations lack appropriate clinical indications. ${ }^{12,13,18}$ Finally, although we have confidence that the timing and magnitude of the changes seen in test-ordering patterns resulted from the withdrawal of insurance coverage, we are less sure of the factors that influenced the pre- and postintervention slopes. These may have been influenced by educational initiatives, such as Choosing Wisely, designed to reduce unnecessary investigation of uncomplicated back pain. ${ }^{10}$

\section{Conclusion}

Our findings show that reimbursement restrictions can modify family physicians' patterns of ordering of imaging for low back pain and that there was little effect on specialists' behaviour. The effects we observed were modest, and some were sustained. They represent a trend toward more appropriate imaging, less radiation exposure for the population and cost savings for the payer.

\section{References}

1. Chou R, Fu R, Carrino JA, et al. Imaging strategies for low-back pain: systematic review and meta-analysis. Lancet 2009;373:463-72.

2. Chou D, Samartzis D, Bellabarba C, et al. Degenerative magnetic resonance imaging changes in patients with chronic low back pain: a systematic review. Spine 2011;36(Suppl):S43-53.

3. Chou R, Deyo RA, Jarvik JG. Appropriate use of lumbar imaging for evaluation of low back pain. Radiol Clin North Am 2012;50:569-85.

4. Flynn TW, Smith B, Chou R. Appropriate use of diagnostic imaging in low back pain: a reminder that unnecessary imaging may do as much harm as good. 7 Orthop Sports Phys Ther 2011;41:838-46.

5. Dagenais S, Tricco AC, Haldeman S. Synthesis of recommendations for the assessment and management of low back pain from recent clinical practice guidelines. Spine 7 2010;10:514-29.

6. National Collaborating Centre for Primary Care (UK). Low back pain: early management of persistent non-specific low back pain. London: Royal College of General Practitioners; 2009.

7. 2012 CAR diagnostic imaging referral guidelines. Saint-Laurent (QC): Canadian Association of Radiologists; 2012
8. Chou R, Qaseem A, Snow V, et al. Diagnosis and treatment of low back pain: a joint clinical practice guideline from the American College of Physicians and the American Pain Society. Ann Intern Med 2007;147:478-91.

9. Imaging tests for lower-back pain. Philadelphia: Consumer Reports; 2012. Available: www.choosingwisely.org/patient-resources/imaging-tests-for-back-pain/ (accessed 2016 June 17)

10. Imaging tests for lower back pain: when you need them and when you don't. Toronto: Choosing Wisely Canada; 2014. Available: www.choosingwiselycanada.org/ materials/imaging-tests-for-lower-back-pain-when-you-need-them-and-when -you-dont/ (accessed 2016 June 17).

11. Wolfson D, Santa J, Slass L. Engaging physicians and consumers in conversations about treatment overuse and waste: a short history of the Choosing Wisely campaign. Acad Med 2014;89:990-5.

12. Emery DJ, Shojania KG, Forster AJ, et al. Overuse of magnetic resonance imaging. 7AMA Intern Med 2013;173:823-5.

13. Rosenkrantz AB, Doshi A. Characterizing the performance of the nation's hospitals in the Hospital Outpatient Quality Reporting Program's imaging efficiency measures. 7 Am Coll Radiol 2015;12:166-73.

14. Chou R, Qaseem A, Owens DK, et al.; Clinical Guidelines Committee of the American College of Physicians. Diagnostic imaging for low back pain: advice for high-value health care from the American College of Physicians. Ann Intern Med 2011;154:181-9.

15. Jenkins HJ, Hancock MJ, French SD, et al. Effectiveness of interventions designed to reduce the use of imaging for low-back pain: a systematic review. CMA7 2015;187:401-8.

16. Blackmore CC, Mecklenburg RS, Kaplan GS. Effectiveness of clinical decision support in controlling inappropriate imaging. 7 Am Coll Radiol 2011;8:19-25.

17. Blachar A, Tal S, Mandel A, et al. Preauthorization of CT and MRI examinations: assessment of a managed care preauthorization program based on the ACR Appropriateness Criteria and the Royal College of Radiology guidelines. 7 Am Coll Radiol 2006;3:851-9.

18. Kennedy SA, Fung W, Malik A, et al. Effect of governmental intervention on appropriateness of lumbar MRI referrals: a Canadian experience. $7 \mathrm{Am}$ Coll Radiol 2014;11:802-7.

19. Amendments to the Schedule of Benefits to reflect evidence-informed care. Toronto: Ontario Ministry of Health and Long-Term Care; 2014. Available: www.health.gov.on.ca/en/pro/programs/ecfa/action/primary/lb_sob.aspx (accessed 2014 Dec. 23).

20. Schedule of benefits for physician services under the Health Insurance Act. Toronto: Ontario Ministry of Health and Long-Term Care; 2012.

21. Busse J, Alexander PE, Abdul-Razzak A, et al. Appropriateness of spinal imaging use in Canada. Toronto: Canadian Institutes of Health Research, Institute for Clinical Evaluative Sciences, Manitoba Health, McMaster University; 2013.

22. You JJ. ICES report: appropriateness: the next frontier in the quest for better access to CT and MRI. Healthc Q 2009;12:25-7.

23. Allan GM, Spooner GR, Ivers N. X-ray scans for nonspecific low back pain: a nonspecific pain? Can Fam Physician 2012;58:275.

24. You JJ, Purdy I, Rothwell DM, et al. Indications for and results of outpatient computed tomography and magnetic resonance imaging in Ontario. Can Assoc Radiol 7 2008;59:135-43.

Affiliations: Department of Medical Imaging (Fine, White), University of Toronto; Institute for Clinical Evaluative Sciences (Schultz, Henry); Joint Department of Medical Imaging (Fine, White), University Health Network/Mount Sinai Hospital/Women's College Hospital; Dalla Lana School of Public Health (Henry) and Institute of Health Policy Management and Evaluation (Henry), University of Toronto, Toronto, Ont.; Centre for Research in Evidence-Based Practice (Henry), Bond University, Gold Coast, Australia; Department of Diagnostic Imaging (Fine), Trillium Health Partners, Mississauga, Ont.

Contributors: Susan Schultz, Benjamin Fine and David Henry oversaw the project. Susan Schultz acquired the data, and Susan Schultz and Benjamin Fine conducted data analyses. Benjamin Fine, David Henry and Susan Schultz interpreted the data and led the drafting and revising of the manuscript. All of the authors conceived and designed the project, gave final approval of the version to be published and agreed to be accountable for all aspects of the work.

Disclaimer: This study was supported by the Institute for Clinical Evaluative Sciences (ICES), which is funded by an annual grant from the Ontario Ministry of Health and Long-Term Care (MOHLTC). The opinions, results and conclusions reported in this article are those of the authors and are independent from the funding sources. No endorsement by ICES or the Ontario MOHLTC is intended or should be inferred.

Supplemental information: For reviewer comments and the original submission of this manuscript, please see www.cmajopen.ca/content/5/4/ E760/suppl/DC1. 